CLINICAL STUDY

\title{
MicroRNA expression profile helps to distinguish benign nodules from papillary thyroid carcinomas starting from cells of fine-needle aspiration
}

\author{
Patrizia Agretti ${ }^{1}$, Eleonora Ferrarini ${ }^{1}$, Teresa Rago ${ }^{1}$, Antonio Candelieri $^{4}$, Giuseppina De Marco ${ }^{1}$, Antonio Dimida $^{1}$, \\ Filippo Niccolai ${ }^{1}$, Angelo Molinaro ${ }^{1}$, Giancarlo Di Coscio ${ }^{2,3}$, Aldo Pinchera ${ }^{1}$, Paolo Vitti ${ }^{1}$ and Massimo Tonacchera $^{1}$ \\ ${ }^{1}$ Department of Endocrinology, Research Center of Excellence AmbiSEN and ${ }^{2}$ Section of Cytopathology, Department of Oncology, University of Pisa, Via \\ Paradisa 2, 56124 Pisa, Italy, ${ }^{3}$ University Hospital of Pisa, Pisa, Italy and ${ }^{4}$ Laboratory for Decision Engineering and Health Care Delivery, Department of \\ Electronic Informatics and Systemistics, University of Calabria, Cosenza, Italy \\ (Correspondence should be addressed to T Massimo; Email: mtonacchera@hotmail.com)
}

\begin{abstract}
Objective: MicroRNAs (miRNAs) are small endogenous noncoding RNAs that pair with target messengers regulating gene expression. Changes in miRNA levels occur in thyroid cancer. Fine-needle aspiration (FNA) with cytological evaluation is the most reliable tool for malignancy prediction in thyroid nodules, but cytological diagnosis remains undetermined for $20 \%$ of nodules.

Design: In this study, we evaluated the expression of seven miRNAs in benign nodules, papillary thyroid carcinomas (PTCs), and undetermined nodules at FNA.

Methods: The prospective study included 141 samples obtained by FNA of thyroid nodules from 138 patients. miRNA expression was evaluated by quantitative RT-PCR and statistical analysis of data was performed. Genetic analysis of codon 600 of BRAF gene was also performed.

Results: Using data mining techniques, we obtained a criterion to classify a nodule as benign or malignant on the basis of miRNA expression. The decision model based on the expression of miR-146b, miR-155, and miR-221 was valid for 86/88 nodules with determined cytology (97.73\%), and adopting cross-validation techniques we obtained a reliability of $78.41 \%$. The prediction was valid for 31/53 undetermined nodules with 16 false-positive and six false-negative predictions. The mutated form V600E of BRAF gene was demonstrated in 19/43 PTCs and in 1/53 undetermined nodules. Conclusions: The expression profiles of three miRNAs allowed us to distinguish benign from PTC starting from FNA. When the assay was applied to discriminate thyroid nodules with undetermined cytology, a low sensitivity and specificity despite the low number of false-negative predictions was obtained, limiting the practical interest of the method.
\end{abstract}

European Journal of Endocrinology 167 393-400

\section{Introduction}

MicroRNAs (miRNAs) are short RNA molecules, on average only 22 nucleotides long, functioning as posttranscriptional negative regulators of gene expression. They bind to complementary sequences in $3^{\prime}$ UTR of target mRNA transcripts usually resulting in translational repression, inhibition of protein synthesis, and gene silencing $(1,2)$.

Today, the number of known unique mature human miRNAs is 1921 (miRBase v18 release November 2011), data freely available to all through the web interface at http://www.mirbase.org/; and this number is constantly increasing. miRNAs have been shown to play a key role in the regulation of gene expression and there is evidence that they are involved in a wide variety of physiological cellular processes including differentiation, proliferation, and apoptosis $(3,4)$. Alteration in
miRNA expression is a common finding in malignancy and there are evidences of the involvement of miRNAs in carcinogenesis (5): mature miRNAs may be decreased or upregulated in cancer depending on tumor types, tissues analyzed, or measurement techniques $(6,7)$. miRNAs may function as either tumor suppressors or oncogenes and have been demonstrated to have a tissue-specific pattern of expression in several cancer histologies $(8,9)$.

Thyroid nodules are the most common thyroid disease, with an incidence of $4-7 \%$ in iodine sufficient areas that markedly increases in iodine deficient countries. At histological examination, thyroid nodules are defined as hyperplastic lesions, adenomas, or carcinomas based on a set of specific macroscopic and microscopic features $(10,11,12,13,14)$. Only $5 \%$ of all thyroid nodules harbor malignancy and therefore preoperative differentiation of benign and malignant 
thyroid nodules is crucial. Ultrasound-guided fineneedle aspiration (FNA) cytology is a safe and sensitive diagnostic procedure to distinguish benign from malignant thyroid nodules, but it continues to be limited in the differential diagnosis of follicular lesions of undetermined significance (undetermined cytology) which are found in up to $20 \%$ of FNA (15). The identification and validation of a predictive molecular biomarker panel would be very helpful in distinguishing benign from malignant nodules in patients with undetermined FNA cytology. Several recent studies used miRNA microarrays to demonstrate a characteristic molecular expression pattern to differentiate benign from malignant thyroid nodules $(16,17,18,19,20,21,22,23$, 24, 25, 26), and RT-PCR TaqMan miRNA assay identifies a limited number of miRNAs that are significantly upregulated in malignant thyroid nodules with respect to normal thyroid tissue, hyperplastic thyroid nodules, and multinodular goiter $(16,17,20)$, suggesting miRNA analysis as a promising tool in diagnostic thyroid pathology.

The aim of this study was to measure and validate the expression of a panel of seven mature miRNAs that were described to be preferentially overexpressed in malignant thyroid neoplasms (hsa-miR-146b, hsa-miR-155 (MIR 155), hsa-miR-187 (MIR 187), hsa-miR-197 (MIR 197), hsa-miR-221 (MIR221), hsa-miR-222 (MIR222), and hsa-miR-224 (MIR224) that in the text will be abbreviated as miR-146b, miR-155, miR187, miR-197, miR-221, miR-222, and miR-224 respectively), to distinguish benign and malignant thyroid nodules starting from cells obtained by FNA, and to investigate their diagnostic potential to distinguish thyroid nodules with undetermined cytology.

\section{Materials and methods}

\section{Patients, thyroid FNA samples, and cytological and histological examinations}

Ultrasound-guided FNA cytology was performed as a part of the standard diagnostic protocol for patients with thyroid nodules in the Department of Endocrinology at the University of Pisa in Italy (27). FNA and cytological evaluation were performed in all nodules with a diameter $>10 \mathrm{~mm}$. Great care was used to collect material only from nodular lesions with the help of ultrasound. One hundred and forty-one thyroid samples were collected from 138 patients (100 females of median age $44.6 \pm 11.5$ and 38 males of median age $49.9 \pm 8.4$ years) and included in the study. One female harbored one benign and one papillary thyroid carcinoma (PTC) in her thyroid at the same time; two malignant PTCs were present in the thyroid of one patient; and two undetermined nodules were in the thyroid of another patient. The study was approved by the Local Ethical Committee and informed consent was obtained from all subjects. After the aspirate was smeared for conventional cytology, the leftover material in the needle was dispersed in TRIzol reagent for total RNA extraction and molecular analysis. A specimen was considered as satisfactory if there were six groups of epithelial cells with at least ten cells per group (28). According to FNA cytological analysis, the nodules were classified as benign, undetermined, or follicular lesions of undetermined significance (high to moderate cellularity and the presence of microfollicular pattern of growth and scant colloid), suspicious for malignancy or malignant, and nondiagnostic or inadequate (due to limited cellularity or poor preservation and fixation), following the guidelines of National Cancer Institute Thyroid Fineneedle Aspiration State of the Science Conference (29). We studied the first consecutive 45 benign thyroid nodules and the first consecutive 43 PTCs on the basis of the cytological response. The 45 benign thyroid nodules belonged to 45 patients: 34 females with a median age of $47.2 \pm 11.9$ years and 11 males with a median age of $45.7 \pm 10.3$ years. The 43 PTCs belonged to 42 patients: 27 females with a median age of $44.9 \pm 11.8$ years and 16 males with a median age of $43.4 \pm 15.1$ years.

A validation sample set of 53 consecutive thyroid nodules with undetermined cytology belonged to 52 patients (11 males with a median age of $51.7 \pm 8.1$ years and 41 females with a median age of $43.7 \pm 11.2$ years) and further tested with the established criterion able to classify a nodule as benign or malignant on the basis of miRNAs expression values. Nondiagnostic or inadequate samples (due to limited cellularity or poor preservation and fixation) were not considered for further investigation.

Serum free thyroxin $\left(\mathrm{FT}_{4}\right)$, free triiodothyronine $\left(\mathrm{FT}_{3}\right)$, and $\mathrm{TSH}$ values were in the normal range in all patients. No serum antithyreoglobulin and antithyreoperoxidase antibodies were detectable. Serum calcitonin was undetectable in all patients. All the patients with benign thyroid nodules were followed conservatively for at least 5 years by annual ultrasound examination, while all the patients with PTC and undetermined nodules underwent thyroid surgery soon after completion of the clinical and cytological evaluation. All the nodules with an FNA indicating malignancy were PTCs (30 with the classic form and 13 with the follicular variant) at histological examination. Of the undetermined thyroid nodules, 15 were PTCs (seven with the classic form and eight with the follicular variant of PTCs) and 38 benign lesions at histological examination. Besides the 15 papillary carcinomas, three were microcarcinomas $<1 \mathrm{~cm}$.

\section{Laboratory evaluation of thyroid function}

Serum $\mathrm{FT}_{4}$ and $\mathrm{FT}_{3}$ were measured with a chemiluminescent method (Vitro System, Ortho-Clinical 
Diagnostics, Rochester, NY, USA). TSH was assessed by ultrasensitive commercial chemiluminescent method (Immulite 2000; Diagnostic Products, Los Angeles, CA, USA). TPOAb and $\mathrm{TgAb}$ were measured using a two-step immunoenzymatic assay (AIA-Pack $\mathrm{TgAb}$ and TPOAb; Tosoh, Tokyo, Japan). Serum calcitonin was measured by IRMA (CisBio International, Gif-sur-Yvette, France).

\section{Total RNA isolation}

FNA samples were collected in TRIzol reagent (Invitrogen Life Technologies) and total RNA extraction was performed according to the manufacturer's instructions. The quality of RNA samples was analyzed by microfluidic electrophoretic separation on chip using the Agilent 2100 BioAnalyzer (Agilent Technologies, Inc., Santa Clara, CA, USA).

\section{RT and miRNA quantification by real-time PCR}

For this study, we selected a set of seven miRNAs (miR-146b, miR-155, miR-187, miR-197, miR-221, miR-222, and miR-224) that have been shown to be significantly upregulated in malignant thyroid nodules compared with normal thyroid tissue, benign hyperplastic nodules, and benign nodules from multinodular goiter $(16,17,19,21)$. This set of miRNAs was analyzed using the TaqMan MicroRNA RT kit protocol (Applied Biosystems, Foster City, CA, USA) consisting in a first step of RT with an miRNA-specific primer and in a second step the real-time PCR with TaqMan probes.

Reverse transcriptase reactions were carried out to produce cDNAs in a volume of $15 \mu \mathrm{l}$ using $10 \mathrm{ng}$ total RNA for each sample, $50 \mathrm{nM}$ stem-loop RT primer, $1 \times$ RT buffer, $1 \mathrm{mM}$ each of dNTPs, $3.33 \mathrm{U} / \mu \mathrm{l}$ MultiScribe reverse transcriptase, and $0.25 \mathrm{U} / \mu \mathrm{l}$ RNase inhibitor. After incubation on ice for $5 \mathrm{~min}$, reactions were subjected to the following program of heating: $30 \mathrm{~min}$ at $16^{\circ} \mathrm{C}, 30 \mathrm{~min}$ at $42{ }^{\circ} \mathrm{C}, 5 \mathrm{~min}$ at $85^{\circ} \mathrm{C}$, and hold at $4{ }^{\circ} \mathrm{C}$.

Real-time PCR was performed in triplicate in a 96-well optical plate on the Applied Biosystems 7700 Sequence Detection System. The volume of $20 \mu \mathrm{l}$ of each sample included $1 \times$ TaqMan Universal PCR Master Mix, $1 \mu \mathrm{l}$ specific miRNA Assay Mix (Applied Biosystems), and $1.34 \mu \mathrm{l}$ RT product. The reactions were incubated at $50{ }^{\circ} \mathrm{C}$ for $2 \mathrm{~min}$ and $95^{\circ} \mathrm{C}$ for $10 \mathrm{~min}$, followed by 40 cycles of $95^{\circ} \mathrm{C}$ for $15 \mathrm{~s}$ and $60{ }^{\circ} \mathrm{C}$ for $1 \mathrm{~min}$.

Analysis of relative miRNA expression data was performed using the $\Delta \Delta C_{\mathrm{T}}$ method with the miRNA lethal-7a (Let-7a) as an endogenous control/reference assay. Results were expressed as the amount of target miRNA normalized to the endogenous reference and relative to a calibrator (normal thyroid tissue).

\section{RT and genetic analysis}

One microgram or, when not available, $500 \mathrm{ng}$ total RNA for each sample were reverse transcribed for $1 \mathrm{~h}$ at $42{ }^{\circ} \mathrm{C}$ in a $20 \mu \mathrm{l}$ reaction volume using 200 units of Superscript II reverse transcriptase (Invitrogen Life Technologies) in the presence of $1.5 \mu \mathrm{M}$ random hexamers (Pharmacia Biotech), 0.01 M dithiothreitol, and $1 \mathrm{mM}$ dNTP mix.

All cDNA samples were analyzed for V600E BRAF mutation by PCR amplification of an exon 15 fragment of $B R A F$ gene and by direct sequencing using BygDye Terminator Kit on the ABI PRISM 310 genetic analyzer (Applied Biosystems). Oligonucleotides used for PCR amplification and sequencing and PCR conditions were the following: primer forward, 5'-GGCATGGATTACTTACACGC-3'; reverse, 5'-TTCTGATGACTTCTGGTGCC-3'; annealing temperature, $60{ }^{\circ} \mathrm{C}$; fragment length, $193 \mathrm{bp}$.

\section{Statistical analysis}

To determine differences in expression of the seven miRNAs in the series of 45 benign thyroid nodules and 43 PTCs, the average and the s.D. of each miRNA expression were evaluated. The expression of each miRNA was compared in benign thyroid nodules with respect to PTCs using the Student's t-test; to test the significance, the risk level $(P)$ was set at 0.05 .

To predict malignancy, we adopted Decision Trees (30), a methodology for learning regularities in datasets. In particular, we used WEKA $(31,32)$, an open-source suite for data mining tasks that provides, among other several learning techniques, an implementation of the Decision Trees named J48. All the levels of miRNA expression (88 instances) were used in this study, each labelled with malignant (43 instances) or benign (45 instances) class. Indeed, identifying a thyroid nodule's class was defined as a supervised classification task. Decision Trees have another relevant advantage: they provide an explicit representation of the knowledge extracted from available data, representation easy for people to understand, that allows domain experts to analyze it in order to check for plausibility and to combine it with previously known facts about the domain. Although the learned decision model presented in the following was obtained by using all the available data, we evaluated its reliability on new and unseen cases through a suitable validation technique: the leaveone-out validation (31). This method works in a really simple way: an instance is removed from the training set and taken apart, while the remaining instances are used for learning a decision model, which may then be adopted to predict the class for the instance previously removed. The entire procedure is repeated for every instance of the training set and then classification errors are counted. Figure 1 shows a schematic representation of the processes aimed at performances evaluation on 


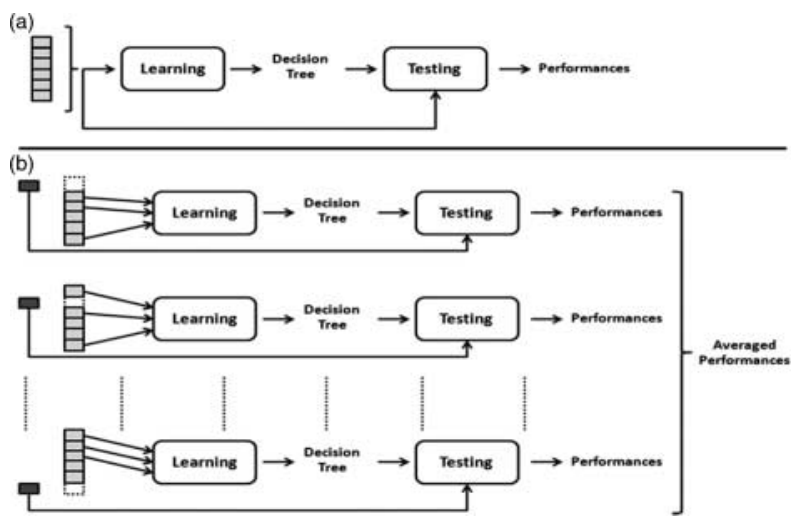

Figure 1 (a) A schematic representation of the dataset usage for the predictive model creation by using the entire data sample and (b) the estimation of predictive model reliability through the leave-one-out validation procedure.

the entire dataset (Fig. 1a) and reliability estimation through leave-one-out validation (Fig. 1b).

Leave-one-out is a $k$-folds cross validation (with $k$ equal to the number of instances) that is generally adopted when the data sample size is not very large; it provides reliable estimation of the prediction capability of the model obtained on the entire dataset and guarantees low variability among the decision trees obtained on each fold.

\section{Results}

In this study, we evaluated a set of seven recently proposed miRNAs and investigated their diagnostic potential to distinguish thyroid nodules with benign or PTC FNA cytology. To confirm the presence of thyroid cells in each sample, the thyroglobulin gene was amplified as described in Tonacchera et al. (33). Thyroglobulin expression was demonstrated in all samples included in the study (data not shown).

The expression of miRNAs miR-146b, miR-155, miR-187, miR-197, miR-221, miR-222, and miR-224 was demonstrated in all the specimens. A significant increase (Student's t-test, $P<0.05$ ) in miR-146b, miR-155, miR-187, miR-221, miR-222, and miR-224 was observed in PTCs with respect to benign thyroid nodules (Table 1). In particular, miR-146b is the one with the greatest increase, which is being expressed $>30$-fold in PTCs than in benign nodules. An increase in miR-197 expression level was also observed in PTC nodules vs benign ones, but this difference was not significant (Table 1).

The decision tree learned from the available dataset is depicted in Fig. 2. Looking at the decision tree, it is easy to notice how rules are associated to malignant and benign thyroid nodules. If one of the following rules is satisfied, the prediction for the nodule is of benignity:
- if miR-146b is lower than 0.48 (included);

- if miR-146b is higher than 0.48 and lower than 2.62 (included) and, at the same time, miR-221 is higher than 0.047 and lower than 56.88 (included);

- if miR-146b is higher than 2.62 and lower than 5.46 and, at the same time, miR-155 is higher than 11.08; and

- if miR-146b is higher than 5.46 and, at the same time, miR-155 is higher than 86.22.

On the other hand, if none of the previous rules is satisfied, then one of the following will be the prediction for nodule malignity:

- if miR-146b is higher than 2.62 and, at the same time, miR-155 is lower than 11.08 (included);

- if miR-146b is higher than 0.48 and, at the same time, miR-221 is lower than 0.047 (included);

- if miR-146b is higher than 0.48 and, at the same time, miR-221 is higher than 56.88; and

- if miR-146b is higher than 5.46 and, at the same time, miR-155 is higher than 11.08 and lower than 86.22 (included).

Each nodule may meet one and only one rule of the decision tree, therefore one nodule for the model is unambiguously benign or malignant. In particular, the first four rules covered 44/45 (corresponding to $97.77 \%$ ) benign cases in our dataset but it also covered one malignant case (one false-negative prediction), while the last four rules covered 42/43 (corresponding to $97.67 \%$ ) malignant cases in our dataset but it also covered one benign case (one false-positive prediction). In summary, the decision model is valid for $86(42$ malignant and 44 benign) of 88 cases $(97.73 \%)$, with a total of one false-positive and one false-negative prediction $(2.27 \%)$. As these results are related to an entire available dataset, model reliability in predicting unknown samples was evaluated through the leaveone-out validation technique. Through this technique a reliability of $78.41 \%$ was determined, which was a lower value than that obtained from the entire sample,

Table 1 miRNAs expression in benign nodules and PTCs. Values are expressed as average \pm S.D. The Student's $t$-test was used to analyze the difference between the averages of the two datasets $(P<0.05)$.

\begin{tabular}{lccr}
\hline miRNA & $\begin{array}{c}\text { Benign } \\
\text { thyroid } \\
\text { nodules }\end{array}$ & $\begin{array}{c}\text { Malignant } \\
\text { thyroid } \\
\text { nodules }\end{array}$ & $\begin{array}{c}\boldsymbol{t} \text {-test } \\
(P \text { value })\end{array}$ \\
\hline $146 \mathrm{~b}$ & $4.2 \pm 15.4$ & $127.2 \pm 239.1$ & $<0.05$ \\
155 & $8.9 \pm 22.7$ & $19.3 \pm 22.3$ & $<0.05$ \\
187 & $6.8 \pm 19.5$ & $75.9 \pm 189.4$ & $<0.05$ \\
197 & $3.8 \pm 9.4$ & $8.6 \pm 33.4$ & 0.35 \\
221 & $41.3 \pm 108.9$ & $195.7 \pm 301.3$ & $<0.05$ \\
222 & $22.2 \pm 97.2$ & $83.1 \pm 166.4$ & $<0.05$ \\
224 & $0.8 \pm 1.8$ & $7.1 \pm 19.5$ & $<0.05$ \\
\hline
\end{tabular}




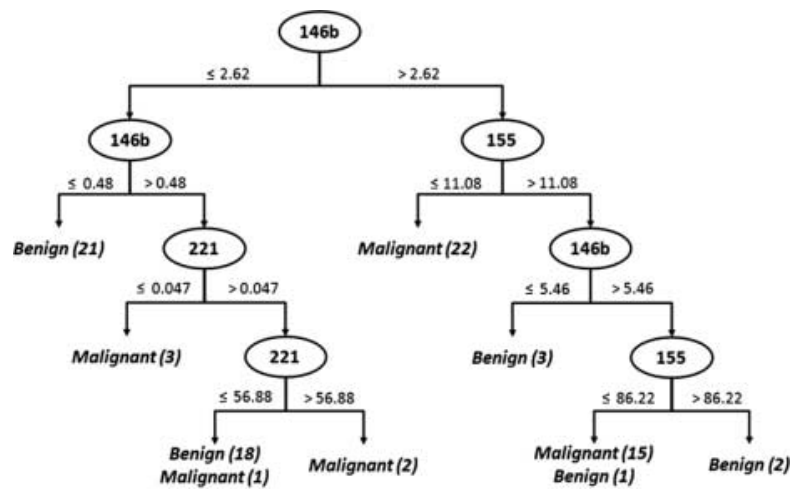

Figure 2 Decision tree. Classification of benign nodules and PTCs on the basis of miR-146b, miR-221, and miR-155 expression. miRNAs are in oval shapes, thresholds for miRNA expression are on the edges and numbers of malignant and benign cases are reported in brackets.

but still very satisfactory as prediction capability on new cases. In Fig. 3, the performances of the model on the entire training set and on the leave-one-out validation phase are reported in order to evaluate over-fitting and generalization. The learned decision model also proved reliable on validation, showing high sensitivity $(79.07 \%)$ and specificity $(77.77 \%)$. Furthermore, accuracy on validation suggests that a good reliability of the prediction (about $78.41 \%$ ) may also be achieved on unknown instances. Similar results were obtained using this decision model analyzing 15 PTC samples not included in the study group (data not shown).

A validation sample set of 53 undetermined thyroid nodules was tested with the established criterion able to classify a nodule as benign or malignant on the basis of miRNA expression values. Of the 53 undetermined thyroid nodules, 15 were PTCs and 38 were benign lesions at histological examination. In 31 cases, the malignant/benign prediction was valid and in 22 cases it was not concordant with the histological examination. In particular, 22 nodules predicted to be benign were benign (true-negative), nine nodules predicted to be malignant were malignant (true-positive), while six nodules predicted to be benign were malignant (falsenegative), and 16 nodules predicted to be malignant were benign (false-positive). In summary, the decision model was valid for 31 of 53 cases $(59 \%)$, with a total of 16 false-positive $(30 \%)$ and six false-negative predictions (11\%), showing a decrease, especially in sensitivity with respect to the training and validation set (Table 2).

Genetic analysis of codon 600 of BRAF gene was performed on the cDNA obtained from all samples. The mutated form V600E of BRAF gene in the heterozygous state was demonstrated by direct sequencing in $19 / 43(44 \%)$ PTCs, in 0/45 benign thyroid nodules, and in only $1 / 53(1.8 \%)$ undetermined thyroid nodules.

\section{Discussion}

The primary goal of the evaluation of patients with nodular thyroid disease is the exclusion of thyroid malignancy. Although FNA cytology represents the most sensitive and specific tool for the differential diagnosis of thyroid malignancy $(15,27,34)$, there are important limitations. While $75 \%$ of FNA reveals a benign, and $5 \%$ a malignant lesion, up to $20 \%$ of FNA reveal follicular lesions of undetermined significance (undetermined cytology) for which surgery is the only method to differentiate between follicular adenoma, follicular carcinoma, and the follicular variant of papillary carcinoma $(35,36)$. In the clinical setting, in case of FNA showing undetermined cytology, molecular markers would be helpful. A genetic approach to improve the pre-operative diagnostic accuracy is to identify a panel of mutations (BRAF and RAS mutations; RET/PTC and PAX8-PPAR $\gamma$ chromosomal rearrangements). These typically mutually exclusive mutations occur in $\sim 70 \%$ of patients with PTC $(37,38,39,40,41)$ and the most frequent alteration is somatic BRAF V600E mutation ( $45 \%$ of PTC). However, a negative test does not exclude the presence

\begin{tabular}{lcc}
\hline & Training set & Leave-one-out \\
\hline Accuracy & $97.73 \%$ & $78.41 \%$ \\
Sensitivity & $97.67 \%$ & $79.07 \%$ \\
Specificity & $97.77 \%$ & $77.77 \%$ \\
\hline
\end{tabular}

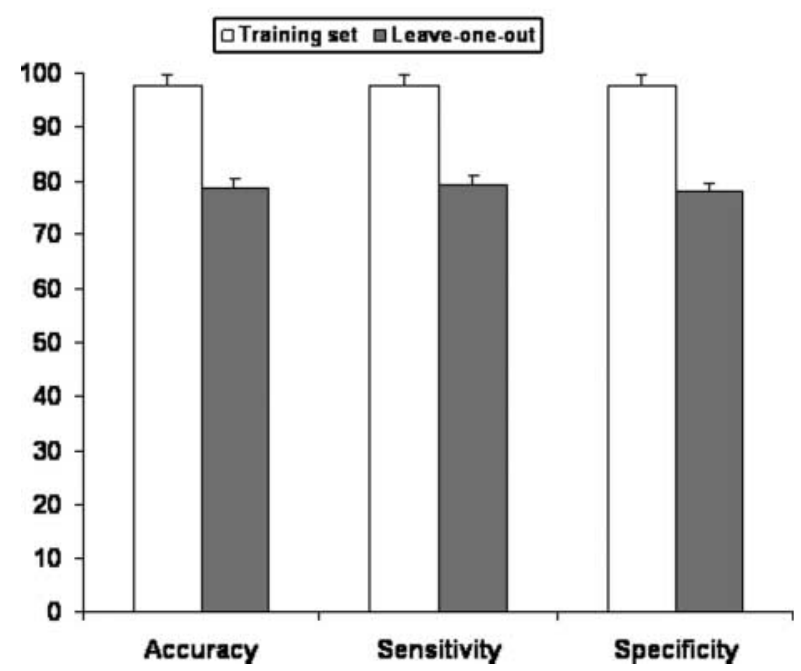

Figure 3 Performances on the entire training set and on the validation phase in terms of reliability indices (accuracy, sensitivity, and specificity). The white columns represent the accuracy, sensitivity, and specificity of the training set, while the gray columns represent the accuracy, sensitivity, and specificity of the validation phase. The comparison permits the evaluation of over-fitting and, furthermore, how reliable the tree is to provide a prediction on new cases. The table shows the numerical values that are graphically represented in this figure. 
Table 2 Performances of the decision model to correctly classify a thyroid nodule with undetermined cytology as benign or malignant.

\begin{tabular}{llllc}
\hline $\begin{array}{l}\text { Histological } \\
\text { diagnosis }\end{array}$ & $\begin{array}{l}\text { Model } \\
\text { prediction }\end{array}$ & $\begin{array}{l}\text { Number of } \\
\text { undetermined } \\
\text { nodules }\end{array}$ & Category & $\begin{array}{c}\text { Percentage } \\
(\%)\end{array}$ \\
\hline Benign & Benign & $22 / 53$ & True-negative & 42 \\
Malignant & Malignant & $9 / 53$ & True-positive & 17 \\
Benign & Malignant & $16 / 53$ & False-positive & 30 \\
Malignant & Benign & $6 / 53$ & False-negative & 11 \\
\hline
\end{tabular}

of a PTC. Unfortunately, the follicular variant of PTC is often negative for $B R A F$ and RAS mutations or RET/PTC rearrangement, thus making the molecular diagnosis difficult in this form of cancer that on the other hand is commonly found in nodules with undetermined cytology (37).

Recently, there has been increasing interest in examining the expression profile of miRNAs in thyroid cancer to understand tumorigenesis and to improve thyroid cancer diagnosis $(16,17,18,19,20,21,22$, 23, 24, 25, 26). He et al. (16) detected preliminary evidence of a potential role for miRNA in PTC. Many studies identified numerous miRNAs transcriptionally upregulated in PTC compared with unaffected thyroid tissue $(17,18,19,20,21,22,23,24,25)$. Kitano et al. (26) described miR-7 as a helpful adjunct marker to thyroid FNA biopsy (FNAB) in tumor types which are inconclusive. In particular, this marker had high negative predictive value. Weber et al. (18), using a high-density miRNA chip platform, identified four miRNAs overexpressed in follicular thyroid carcinoma compared with follicular thyroid adenoma, demonstrating that only a few miRNAs are deregulated between these two kinds of tumors. Different miRNAs have been shown to be deregulated in anaplastic carcinomas (42), providing evidence that various histopathological types of thyroid tumors show significantly different profiles of miRNA expression (43). Recently, miR-146b, miR-155, miR-187, miR-197, miR-221, miR-222, and miR-224 were selected by Nikiforova et al. (21) on the basis of at least twofold overexpression in thyroid cancers compared with hyperplastic nodules and their upregulation in different types of thyroid cancer in surgical samples. This set of miRNA was validated by the same authors in FNA samples showing high accuracy of thyroid cancer detection (21).

In this study, we used a panel of seven miRNAs obtained from reviewing the literature, and we analyzed the level of expression of each miRNA by using quantitative RT-PCR in a prospective series of 141 samples obtained by FNA of thyroid nodules: 45 with benign, 43 PTCs, and 53 with undetermined cytological diagnosis. Statistical analysis was performed to determine differences in expression of the seven miRNAs (Student's $t$-test) and to perform a prediction of malignancy (J48 Decision Trees). An increase in all miRNAs analyzed was detected in PTCs with respect to benign nodules, but only miR-146b, miR-155, miR-187, miR-221, miR-222, and miR-224 expression was significantly increased $(P<0.05)$. The decision model obtained, based on the expression of only three miRNAs (miR-146b, miR-155, and miR-221), was valid for 86 (42 malignant and 44 benign) of 88 cases $(97.73 \%)$, with a total of one false-positive and one false-negative predictions $(2.27 \%)$. The obtained malignant/benign prediction was also valid for 31 of 53 cases $(59 \%)$ of nodules with undetermined cytology with a total of 16 false-positive and six false-negative predictions. Obviously, the matter that mostly concerns us is the six false-negative predictions corresponding to $11 \%$. Different factors may contribute to the false-negative results such as poor RNA quality and low proportion of malignant cells in FNA samples. It is possible that too few cells were removed by FNA in cases of undetermined nodules and were not able to give a definitive diagnostic response from either a cytological or a biomolecular point of view. In the same samples, we showed the mutated form V600E of BRAF gene in the heterozygous state in $44 \%$ of PTCs, and in none of the 56 benign thyroid nodules. Besides only one sample of a thyroid nodule with undetermined cytology, at histological examination a PTC showed a heterozygous V600E mutation in the BRAF gene.

Our data are in agreement with those obtained in a recent study (25) performed on RNA extracted from extra slides of FNA samples of nodules in which 30 atypia cases were analyzed, by using a set of four miRNAs that could best differentiate malignant from benign lesions in these thyroid FNA samples. However, when applied on FNAs that read as atypia of undetermined significance, this panel was inaccurate in obtaining a diagnostic accuracy of about $73 \%$. Similar results have been obtained by Sheu et al. (22) who analyzed a set of five miRNAs in RNA of formalinfixed paraffin-embedded thyroid tissues and found that this set of miRNA could distinguish PTC from benign nodules but failed in the differential diagnosis of encapsulated follicular thyroid carcinoma.

In conclusion, our results confirmed that: i) the material obtained from FNA samples is sufficient to extract high-quality RNA to analyze the expression of miRNAs; ii) the expression of miR-146b, miR-187, and miR-224 was significantly increased in PTCs with respect to benign nodules and miR-146b was the most upregulated miRNA; iii) the expression profile of only three miRNAs (miR-146b, miR-155, and miR-221) allowed a good prediction for distinguishing benign from PTCs starting from FNA samples; and iv) the malignant/benign prediction was valid for about $60 \%$ of nodules with undetermined cytology with a total of only $11 \%$ false-negative predictions, improving the diagnostic accuracy of FNA. 


\section{Declaration of interest}

The authors declare that there is no conflict of interest that could be perceived as prejudicing the impartiality of the research reported.

\section{Funding}

This work was supported by the following grants: Ministero dell'Università e della Ricerca Scientifica e Tecnologica (MURST), Programma di Ricerca: Protein, Metabolomic, fingerprint, and gene expression profile of thyroid nodules with follicular proliferation cytology: identification of new markers to distinguish benign and malignant thyroid nodules. Ministero della Sanità, Ricerca Finalizzata: Indagine sulla associazione fra malattie congenite tiroidee e malattie neuropsichiche rare: studi genetico-molecolari e funzionali.

\section{Acknowledgements}

We are grateful to MURST and Ministero della Sanità for funding.

\section{References}

1 Bartel DP. MicroRNAs: genomics, biogenesis, mechanism, and function. Cell $2004 \mathbf{1 1 6}$ 281-297. (doi:10.1016/S00928674(04)00045-5)

2 Bartel DP. MicroRNAs: target recognition and regulatory functions. Cell 2009136 215-233. (doi:10.1016/j.cell.2009.01.002)

3 Hatfield SD, Shcherbata HR, Fischer KA, Nakahara K, Carthew RW \& Ruohola-Baker H. Stem cell division is regulated by the microRNA pathway. Nature 2005435 974-978. (doi:10. 1038/nature03816)

4 Farh KK, Grimson A, Jan C, Lewis BP, Johnston WK, Lim LP, Burge CB \& Bartel DP. The widespread impact of mammalian microRNAs on mRNA repression and evolution. Science 2005310 1817-1821. (doi:10.1126/science.1121158)

5 Esquela-Kerscher A \& Slack FJ. Oncomirs - microRNAs with a role in cancer. Nature Reviews Cancer 20066 259-269. (doi:10.1038/ nrc1840)

6 Lu J, Getz G, Miska EA, Alvarez-Saavedra E, Lamb J, Peck D, SweetCordero A, Ebert BL, Mak RH, Ferrando AA, Downing JR, Jacks T, Horvitz HR \& Golub TR. MicroRNA expression profiles classify human cancers. Nature 2005435 834-838. (doi:10.1038/ nature03702)

7 Volinia S, Calin GA, Liu CG, Ambs S, Cimmino A, Petrocca F, Visone R, Iorio M, Roldo C, Ferracin M, Prueitt RL, Yanaihara N, Lanza G, Scarpa A, Vecchione A, Negrini M, Harris CC \& Croce CM. A microRNA expression signature of human solid tumors defines cancer gene targets. PNAS 2006103 2257-2261. (doi:10.1073/ pnas.0510565103)

8 Hammond SM. MicroRNAs as oncogenes. Current Opinion in Genetics \& Development 200616 4-9. (doi:10.1016/j.gde.2005. 12.005)

9 Hammond SM. MicroRNAs as tumor suppressors. Nature Genetics 200739 582-583. (doi:10.1038/ng0507-582)

10 Rosaj J, Carcangiu ML \& De Lellis RA. Tumors of the thyroid gland. In Atlas of Tumor Pathology, third series, pp 21-47. Washington, DC: Armed Forces Institute of Pathology (AFIP), 1992.

11 Mazzaferri EM. Management of a solitary thyroid nodule. New England Journal of Medicine 1993328 553-559. (doi:10.1056/ NEJM199302253280807)

12 Tan GH \& Gharib H. Thyroid incidentalomas: management approaches to non-palpable nodules discovered incidentally on thyroid imaging. Annals of Internal Medicine 1997126 226-231.

13 Rago T, Chiovato L, Aghini-Lombardi F, Grasso L, Pinchera A \& Vitti P. Non-palpable thyroid nodules in a borderline iodinesufficient area: detection by ultrasonography and follow-up. Journal of Endocrinological Investigation 200124 770-776.
14 American Association of Clinical Endocrinologists and Associazione Medici Endocrinologi. Medical guidelines for clinical practice for the diagnosis and management of thyroid nodules. AACE/AME Task Force on Thyroid Nodules. Endocrine Practice 200612 63-102.

15 Gharib H. Fine-needle aspiration biopsy of the thyroid nodules: advantages, limitations and effect. Mayo Clinic Proceedings 1994 69 44-49.

16 He H, Jazdzewski K, Li W, Liyanarachchi S, Nagy R, Volinia S, Calin GA, Liu CG, Franssila K, Suster S, Kloos RT, Croce CM \& de la Chapelle A. The role of microRNA genes in papillary thyroid carcinoma. PNAS 2005102 19075-19080. (doi:10.1073/pnas. 0509603102)

17 Pallante P, Visone R, Ferracin M, Ferraro A, Berlingieri MT, Troncone G, Chiappetta G, Liu CG, Santoro M, Negrini M, Croce CM \& Fusco A. MicroRNA deregulation in human thyroid papillary carcinomas. Endocrine-Related Cancer 200613 497-508. (doi:10.1677/erc.1.01209)

18 Weber F, Teresi RE, Broelsch CE, Frilling A \& Eng C. A limited set of human microRNA is deregulated in follicular thyroid carcinoma. Journal of Clinical Endocrinology and Metabolism 200691 3584-3591. (doi:10.1210/jc.2006-0693)

19 Tetzlaff MT, Liu A, Xu X, Master SR, Baldwin DA, Tobias JW, Livolsi VA \& Baloch ZW. Differential expression of miRNAs in papillary thyroid carcinoma compared to multinodular goiter using formalin fixed paraffin embedded tissues. Endocrine Pathology 200718 163-173. (doi:10.1007/s12022-007-0023-7)

20 Chen YT, Kitabayashi N, Zhou XK, Fahey TJ III \& Scognamiglio T. MicroRNA analysis as a potential diagnostic tool for papillary thyroid carcinoma. Modern Pathology: an Official Journal of the United States and Canadian Academy of Pathology, Inc. 200821 1139-1146. (doi:10.1038/modpathol.2008.105)

21 Nikiforova MN, Tseng GC, Steward D, Diorio D \& Nikiforov YE. MicroRNA expression profiling of thyroid tumors: biological significance and diagnostic utility. Journal of Clinical Endocrinology and Metabolism 200893 1600-1608. (doi:10.1210/jc.2007-2696)

22 Sheu SY, Grabellus F, Schwertheim S, Worm K, Broecker-Preuss M \& Schmid KW. Differential miRNA expression profiles in variants of papillary thyroid carcinoma and encapsulated follicular thyroid tumours. British Journal of Cancer 2010102 376-382. (doi:10. 1038/sj.bjc.6605493)

23 Colamaio M, Borbone E, Russo L, Bianco M, Federico A, Califano D, Chiappetta G, Pallante P, Troncone G, Battista S \& Fusco A. miR191 down-regulation plays a role in thyroid follicular tumors through CDK6 targeting. Journal of Clinical Endocrinology and Metabolism 201196 1915-1924. (doi:10.1210/jc.2011-0408)

24 Mazeh H, Mizrahi I, Halle D, Ilyayev N, Stojadinovic A, Trink B, Mitrani-Rosenbaum S, Roistacher M, Ariel I, Eid A, Freund HR \& Nissan A. Development of a microRNA-based molecular assay for the detection of papillary thyroid carcinoma in aspiration biopsy samples. Thyroid 201121 111-118. (doi:10.1089/thy.2010. 0356)

25 Shen R, Liyanarachchi S, Li W, Wakely PE Jr, Saji M, Huang J, Nagy R, Farrell T, Ringel MD, de la Chapelle A, Kloos RT \& He H. MicroRNA signature in thyroid fine needle aspiration cytology applied to "atypia of undetermined significance" cases. Thyroid 201222 9-16. (doi:10.1089/thy.2011.0081)

26 Kitano M, Rahbari R, Patterson EE, Steinberg SM, Prasad NB, Wang Y, Zeiger MA \& Kebebew E. Evaluation of candidate diagnostic microRNAs in thyroid fine-needle aspiration biopsy samples. Thyroid 201222 285-291. (doi:10.1089/thy.2011. 0313)

27 Rago T, Di Coscio G, Basolo F, Scutari M, Elisei R, Berti P, Micoli P, Romani R, Faviana P, Pinchera A \& Vitti P. Combined clinical, thyroid ultrasounds, and cytological features help to predict thyroid malignancy in follicular and Hürtle cell thyroid lesions: results from a series of 505 consecutive patients. Clinical Endocrinology 200666 13-20. (doi:10.1111/j.1365-2265.2006. 02677.x)

28 Baloch ZW \& LiVolsi VA. Fine needle aspiration of thyroid nodules: past, present and future. Endocrine Practice 200410 234-241. 
29 Baloch ZW, LiVolsi VA, Asa SL, Rosai J, Merino MJ, Randolph G, Vielh P, DeMay RM, Sidawy MK \& Frable WJ. Diagnostic terminology and morphologic criteria for cytologic diagnosis of thyroid lesions: a synopsis of the National Cancer Institute Thyroid Fine-Needle Aspiration State of the Science Conference. Diagnostic Cytopathology 200836 425-434. (doi:10.1002/dc.20830)

30 Quinlan JR. Induction of decision trees. Machine Learning 19861 81-106.

31 Witten IH \& Frank E. Data Mining: Practical Machine Learning Tools and Techniques with Java Implementation 2000. San Francisco: Morgan Kaufmann.

32 Hall M, Frank E, Holmes G, Pfahringer B, Reutemann P \& Witten IH. The WEKA Data Mining Software: an Update. SIGKDD Explorations 200911 10-18.

33 Tonacchera M, Agretti P, Rago T, De Marco G, Niccolai F, Molinaro A, Scutari M, Candelieri A, Conforti D, Musmanno R, Di Coscio G, Basolo F, Iacconi P, Miccoli P, Pinchera A \& Vitti P. Genetic markers to discriminate benign and malignant thyroid nodules with undetermined cytology in an area of borderline iodine deficiency. Journal of Endocrinological Investigation 2011 In press. (doi: $10.3275 / 8012$ )

34 Rago T, Fiore E, Scutari M, Santini F, Di Coscio G, Romani R, Piaggi P, Ugolini C, Basolo F, Miccoli P, Pinchera A \& Vitti P. Male sex, single nodularity, and young age are associated with the risk of finding a papillary thyroid cancer on fine-needle aspiration cytology in a large series of patients with nodular thyroid disease. European Journal of Endocrinology 2010162 763-770. (doi:10. 1530/EJE-09-0895)

35 Smith J, Cheifetz RE, Schneidereit N, Berean K \& Thomson T. Can accurately predict benign follicular nodules? American Journal of Surgery 2005189 592-595. (doi:10.1016/j.amjsurg. 2005.01.028)

36 Carling T \& Udelsman R. Follicular neoplasm of the thyroid: what to recommend. Thyroid 200515 583-587. (doi:10.1089/thy. 2005.15.583)

37 Ferraz C, Eszlinger M \& Paschke R. Current state and future perspective of molecular diagnosis of fine-needle aspiration biopsy of thyroid nodules. Journal of Clinical Endocrinology and Metabolism 201196 2016-2026. (doi:10.1210/jc.2010-2567)
38 Nikiforova MN \& Nikiforov YE. Molecular diagnostics and predictors in thyroid cancer. Thyroid 200919 1351-1361. (doi:10.1089/thy.2009.0240)

39 Lo Sapio MR, Posca D, Raggioli A, Guerra A, Marotta V, Deandrea M, Motta M, Limone PP, Troncone G, Caleo A, Rossi G, Fenzi G \& Vitale M. Detection of RET/PTC, TRK and BRAF mutations in preoperative diagnosis of thyroid nodules with indeterminate cytological findings. Clinical Endocrinology $2007 \mathbf{6 6}$ 678-683. (doi:10.1111/j.1365-2265.2007.02800.x)

40 Nikiforov YE, Steward DL, Robinson-Smith TM, Haugen BR, Klopper JP, Zhu Z, Fagin JA, Falciglia M, Weber K \& Nikiforova MN. Molecular testing for mutations in improving the fine-needle aspiration diagnosis of thyroid nodules. Journal of Clinical Endocrinology and Metabolism 200994 2092-2098. (doi:10. 1210/jc.2009-0247)

41 Pelizzo MR, Boschin IM, Barollo S, Pennelli G, Toniato A, Zambonin L, Vianello F, Piotto A, Ide EC, Pagetta C, Sorgato N, Torresan F, Girelli ME, Nacamulli D, Mantero F \& Mian C. BRAF analysis by fine needle aspiration biopsy of thyroid nodules improves preoperative identification of papillary thyroid carcinoma and represents a prognostic factor. A mono-institutional experience. Clinical Chemistry and Laboratory Medicine 201149 325-329. (doi:10.1515/cclm.2011.031)

42 Visone R, Pallante P, Vecchione A, Cirombella R, Ferracin M, Ferraro A, Volinia S, Coluzzi S, Leone V, Borbone E, Liu CG, Petrocca F, Troncone G, Calin GA, Scarpa A, Colato C, Tallini G, Santoro M, Croce CM \& Fusco A. Specific microRNAs are downregulated in human thyroid anaplastic carcinomas. Oncogene 200726 7590-7595. (doi:10.1038/sj.onc.1210564)

43 de la Chapelle A \& Jazdzewski K. MicroRNAs in thyroid cancer. Journal of Clinical Endocrinology and Metabolism 2011963326 3336. (doi:10.1210/jc.2011-1004)

Received 21 December 2011

Revised version received 20 June 2012

Accepted 22 June 2012 